\title{
Reseña proyecto de Extensión «De la tierra al barro, entre el arte y la tecnología: recuperación y puesta en valor de saberes $y$ prácticas alfareras ancestrales» ${ }^{1}$
}

Jimena Blasco, ${ }^{2}$ Bruno Gentile, ${ }^{2}$ Vilma Bada, ${ }^{3}$ Bárbara Escobar, ${ }^{4}$ Martín Iribarren, ${ }^{3}$ Eugenia Villarmarzo ${ }^{2}$

\section{Resumen}

Se presenta aquí un relato sintético de las actividades llevadas a cabo en 2018 el marco de un Proyecto de Fortalecimiento de Trayectorias Integrales (Comisión Sectorial de Extensión y Actividades en el Medio -CSEAM-, Universidad de la República). Tal como indican las bases de estos proyectos los objetivos estuvieron encaminados a conformar un equipo interdisciplinario para la promoción de la integración de las funciones universitarias. En este caso, el trabajo estuvo centrado en el conocimiento sobre la tecnología cerámica prehispánica, así como una profundización del lenguaje plástico utilizado. En este proceso tanto los actores involucrados (ceramistas del departamento de Rocha) como docentes, estudiantes y egresados de Facultad de Humanidades y Ciencias de la Educación (FHCE), del Instituto Escuela Nacional de Bellas Artes (IENBA) y del Centro Universitario Regional Este (CURE) fuimos parte de un aprendizaje conjunto. Por otra parte, se trató de una indagación y reflexión colectiva sobre los sentidos cerámicos locales actuales y pasados con el fin de promover la recuperación de los conocimientos prehispánicos y tradicionales contribuyendo de esta forma a revalorizar los saberes locales.

1 Proyecto Fortalecimiento de Trayectorias Integrales (CSEAM 2018). Responsable: Martín Iribarren. Equipo de trabajo: M. Iribarren, C. Gianotti, E. Villarmarzo, J. Blasco, G. Lamas, L. Ramos, B. Gentile, L. Moraiti, V. Cambre, V. Bada, A. Turell, B. Escobar, V. Febrero.

2 Laboratorio de Arqueología del Paisaje y Patrimonio (LAPPU), Facultad de Humanidades y Ciencias de la Educación, Universidad de la República. investigacion@lappu.edu.uy

3 Instituto Escuela Nacional de Bellas Artes (IENBA), CURE, Universidad de la República.

4 Antropóloga. Estudiante de la Escuela de Artes y Artesanías. Dr. Pedro Figari CETP-UTU. 


\section{Introducción y antecedentes}

L objetivo de esta reseña es compartir La experiencia interdisciplinaria y dialógica del proyecto de Fortalecimiento a Trayectorias Integrales titulado «De la tierra al barro, entre el arte y la tecnología: recuperación y puesta en valor de saberes y prácticas alfareras ancestrales", que fue financiado por la CSEAM de la Universidad de la República. Este se desarrolló entre los meses de junio y diciembre de 2018 y tuvo un abordaje interdisciplinario desde su conformación, integrado por estudiantes, docentes y egresados de las carreras de Arqueología, Antropología social, Bellas artes, Gestión ambiental y Museología, así como por ceramistas e instituciones y organizaciones del departamento de Rocha, Uruguay.

Concretamente, la zona de trabajo delimitada es la contemplada dentro del Paisaje Protegido Laguna de Rocha (PPLR) y áreas próximas (La Paloma, Arachania, Santa Isabel, La Pedrera, Valizas y Castillos).

Una de las reflexiones surgidas de las acciones que se han desarrollado en áreas protegidas por el LAPPU, es el carácter preponderante de los aspectos ecológicos por sobre los patrimoniales, así como una persistente demanda de la población local de mayor intercambio de información sobre las investigaciones académicas (Gianotti y otros, 2016). Mediante la propuesta planteada de acciones colaborativas, a través de la realización de prospecciones en conjunto con los pobladores, y de relacionamiento directo con el trabajo del arte cerámico, se trató de favorecer y fortalecer el intercambio de conocimiento, percepciones y valorizaciones, así como reforzar los vínculos y la apropiación del patrimonio. Esta tarea requiere intercambio entre saberes, promoviendo un abordaje interdisciplinario, convergiendo principalmente las de Arqueología y Bellas Artes.

El proyecto fue parte del desarrollo de prácticas integrales y vínculos generados por el LAPPU en el PPLR. Da continuidad a proyectos de investigación y extensión de este Laboratorio y buscó conformar un equipo universitario interdisciplinario con el IENBA. Por un lado, incentivó nuevas acciones de colaboración con la población local que han sido identificadas como demanda y que generaron el compromiso y necesidad de continuidad (Blasco y otros, 2014; Vitancurt, 2016). Por otro, fortaleció el vínculo y extendió la participación a más actores, al tiempo que amplió la zona arqueológica de estudio hacia áreas adyacentes y de influencia directa de la laguna, contempladas dentro de la planificación del área protegida (MVOTMA e IDR, 2016).

Los trabajos de extensión e investigación del LAPPU en el área comenzaron en 2011, en colaboración con la elaboración del Plan de manejo (Futuro Sustentable S.A. 2011; Gianotti y Villarmarzo, 2011) y el Inventario patrimonial del área. Este equipo realizó también varios proyectos de actividades en el medio, ${ }^{5}$ Proyectos Estudiantiles de Extensión ${ }^{6}$, Sistematización de Experiencias de Extensión, ${ }^{7}$ Fortalecimiento de Trayectorias Integrales, ${ }^{8}$ así como un proyecto de la Comisión Sectorial de Investigación Científica (CSIC) de Iniciación a la investigación (Villarmarzo, 2017) y un proyecto de cooperación

5 «A la perinola!», 2012; «Paisajes culturales y diagnóstico participativo en el Museo Regional de Rocha», 2012; «Una laguna, muchas lagunas», 2015, y «Patrimonio en Acción» 2017.

6 «Cartografiando Patrimonios», 2012.

7 «Aprendiendo de nuestras prácticas», 2013.

8 «Hacia la construcción multivocal del Patrimonio Cultural en el PPLR», 2013-2014. 
(Red CYTED TRAMA3 2013-2016) (Blasco y otros, 2014; Blasco, 2014; Gianotti y otros, 2016; Lamas y otros, 2013; Vienni y Blasco, 2014). Vinculado a estos proyectos, se generaron instancias de formación (cursos dictados en el CURE), de participación estudiantil (pasantías, tesis de grado y de posgrado), presentación de resultados en eventos académicos y articulación con otras disciplinas (véanse Gianotti, Villarmarzo y Blasco, 2015a y Gianotti y otros, 2015b). Dichas prácticas permitieron poner en relación diferente actores, instituciones y organizaciones locales.

Durante estas actividades, se llevaron a cabo prospecciones junto a pobladores locales y guardaparques, se relevaron colecciones arqueológicas, se realizaron talleres y mapeamientos participativos, se elaboraron materiales de divulgación y se volcaron los resultados en el blog Patrimonio en Laguna de Rocha y en redes sociales (Facebook@ Patrimonio en Laguna de Rocha). Asimismo se desarrolló una multiplataforma con contenidos patrimoniales (Biendeacá) anclada en la Laguna de Rocha pero también desplegable a todo el país, que permite un mayor intercambio e interacción con las/ los usuarios.

El trabajo con colecciones (Blasco, 2019; Marozzi y Lamas, 2012; Villarmarzo, 2018), derivó en el desarrollo de otra propuesta de extensión orientada al trabajo participativo y colaborativo entre distintos actores e instituciones para elaborar una Guía de buenas prácticas en caso de hallazgos arqueológicos (proyecto «Patrimonio en Acción», CSEAM, 2017).

El LAPPU además realizó dos talleres de elaboración de cerámica prehistórica en el marco del CURE de Puertas abiertas, cuyo antecedente directo es una reconstrucción experimental de una vasija arqueológica de Pago Lindo (Tacuarembó) realizada por una ceramista junto con Camila Gianotti en el Instituto de Ciencias del Patrimonio (Incipit, España). Asimismo, se hizo reconstrucción en 2D y 3D con CAD de cerámica arqueológica del sitio Guayacas (Paysandú) sobre la base de colecciones de referencia de la zona (Blasco, 2013).

Un antecedente clave por otro lado, son los espacios de investigación y formativos desarrollados por el equipo de IENBA junto con arqueólogos/as, en el marco de los cuales se crearon puentes desde la prehistoria al presente, a través del patrimonio local, tal como busca el presente proyecto. La construcción de una plataforma de investigación de estudio con bases de creaciones cerámicas prehispánicas propuso generar una «carta de identidad local» para ser transmitida a través de la enseñanza activa, en una permanente interacción dialógica: estudiante-docente-material de trabajo-medio.

Parte del equipo de IENBA del área Artes del fuego ha realizado investigación junto a propuestas pedagógicas en clave de enseñanza activa en Montevideo y Rocha. En colaboración con un equipo

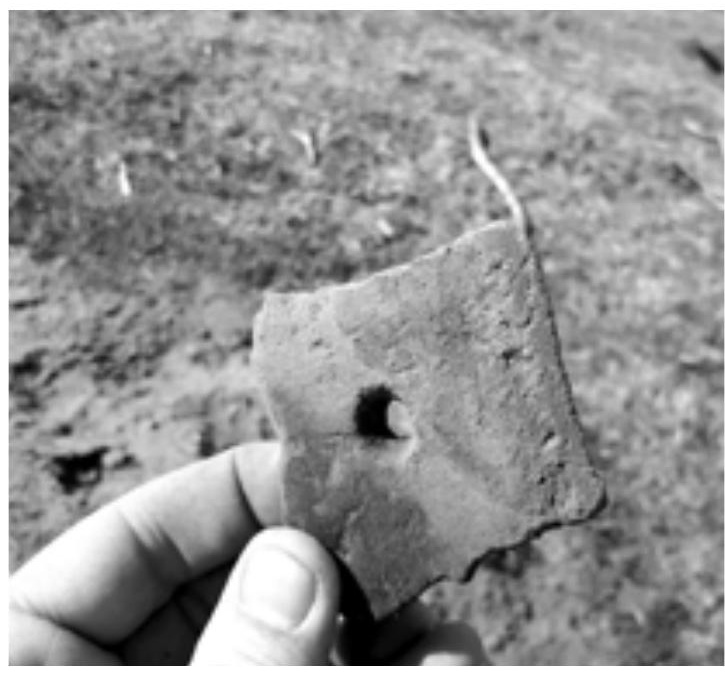


de FHCE se desarrolló en 2005 un catálogo de estilos cerámicos que fue producto de un relevamiento de motivos decorativos indígenas y de la generación de una base de datos asociada (IENBA, 2005). En 2007-2008, se llevó a cabo el proyecto CSIC Sector Productivo «Tipolndígena: diseño experimental de formas modulares nativas orientadas al sector productivo" y se realizaron talleres de Arqueología y diseño para el desarrollo local en el marco de los Fondos Concursables para la Cultura 2008-2009 (Diconca, 2008). El proyecto Tipolndígenas propuso construir un marco teórico a través de la interrelación de distintas disciplinas y áreas de conocimiento, que brindaran patrones morfológicos modulares para la aplicación experimental en el sector productivo. Apostó a la pedagogía y metodologías del IENBA (IENBA, s/d) e implicó orientar las actividades curriculares en un sentido de apoyo permanente en las experiencias vivenciales, como factor generador de nuevas lecturas y enfoques perceptivos del individuo. A partir de estas experiencias, en 2008 el equipo desarrolló el proyecto titulado
«La tradición arqueológica alfarera del litoral para el diseño y desarrollo potencial de emprendimientos artesanales jóvenes» (FCC, MEC) cuyo objetivo fue resemantizar diseños y tecnología alfarera prehistórica, aplicándolos a través de un proceso de diseño a nuevas instancias de producción artesanal local.

\section{Objetivos del proyecto}

Este proyecto aquí presentado buscó - dar continuidad a los procesos colaborativos y multivocales de construcción y gestión del patrimonio cultural en el PPLR y áreas cercanas. Particularmente se buscó promover un ámbito de investigación entre la universidad y la comunidad que propiciara la coconstrucción de conocimientos y sentidos en torno al patrimonio y que fomentara el desarrollo local sustentable a través de su socialización, valorización y uso. Asimismo, se buscó promover el reconocimiento de técnicas y materiales utilizados por nuestros antepasados indígenas, incorporando dichos elementos a la cultura local.

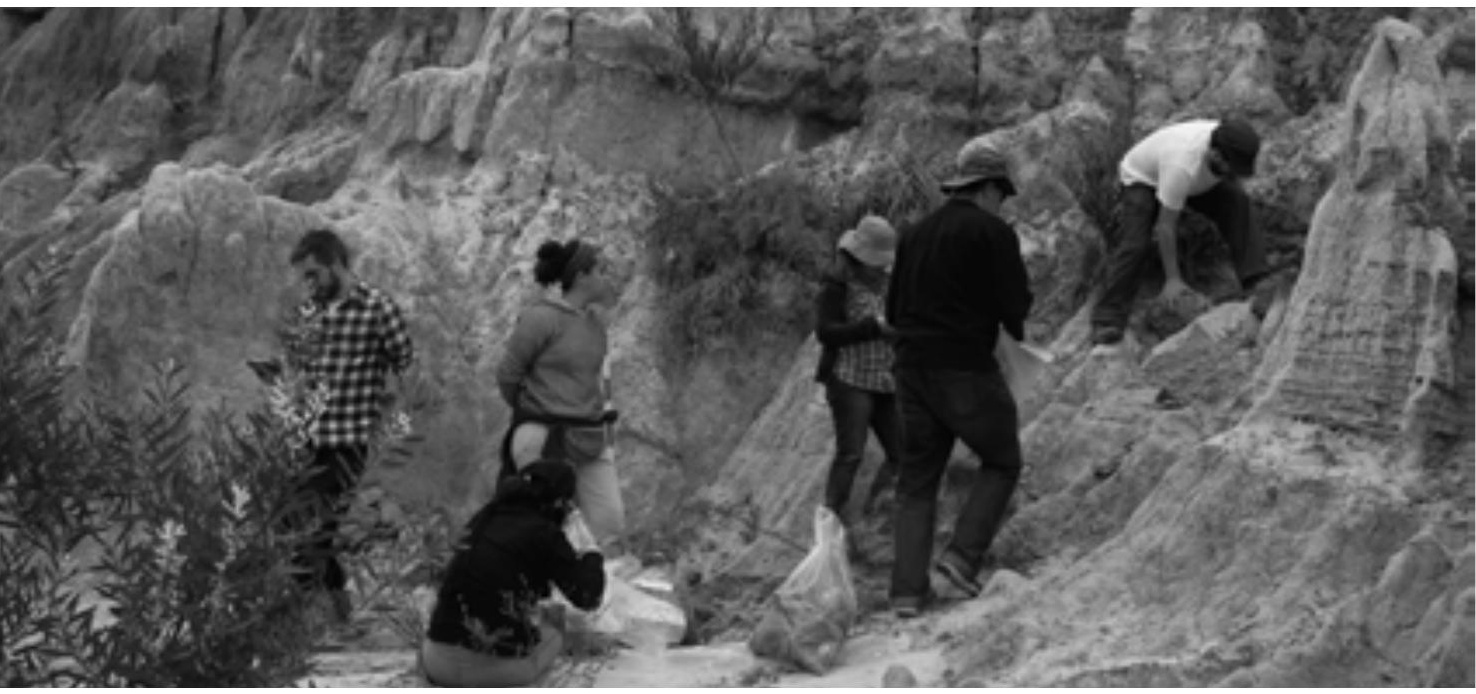


El trabajo de base estuvo relacionado con el reconocimiento y puesta en valor de nuevos sitios arqueológicos y modos de uso y apropiación del espacio que puedan ser socializados e incorporados al inventario del área de Laguna de Rocha. Este objetivo se orientó especialmente, a la investigación y divulgación de las distintas etapas de la cadena operativa de producción de cerámica indígena/tradicional contempladas en la búsqueda de fuentes de aprovisionamiento de materias primas para la elaboración de la cerámica (por ejemplo arcilla, antiplásticos, leña, etc.) y del empleo de técnicas y desarrollo de procedimientos de elaboración, decoración y cocción. Este conocimiento buscó impulsar la participación de la comunidad local junto a varias disciplinas (arqueología, antropología social, bellas artes, gestión ambiental, museología) en los procesos de investigación y gestión, contribuyendo además a la puesta en valor, protección patrimonial y salvaguarda de sitios, saberes y oficios tradicionales.

\section{Actividades y acciones integrales desarrolladas}

D urante los siete meses de trabajo del proyecto, nos concentramos en una serie de actividades que permiten dar inicio a la conformación y formación de un equipo amplio vinculado a la investigación y experimentación sobre la cerámica tradicional (alfarería indígena) que pusiera foco en las técnicas y las prácticas de producción. Estas actividades se realizaron por medio del intercambio de saberes locales y conocimientos técnicos y de la implementación de métodos de enseñanza activa a través de producciones cerámicas utilizando tierras locales (arcillas), técnicas de elaboración tradicionales y horneadas a cielo abierto, como lo hacían los grupos indígenas de nuestro territorio y de la región. Para esto, las actividades consistieron en:

1) Relevamiento bibliográfico y catalogación de colecciones: el proyecto da continuidad a actividades de relevamiento de colecciones arqueológicas de la zona (Blasco, 2019; Villarmarzo 2018). En particular el trabajo estuvo centrado en la sistematización de datos publicados sobre cerámica arqueológica de la zona este de Uruguay y la catalogación de una colección particular formada principalmente por tiestos cerámicos prehispánicos (Figura 1).

2) Intercambio con ceramistas locales y realización de entrevistas semidirigidas: La decisión de realizar las entrevistas con una pequeña guía de consultas pero no rígida fue en relación con la sensibilidad presente en los interlocutores, principalmente personas cuyo oficio es una forma de vida. Estuvimos junto a ceramistas en formación en el taller de la Junta de La Paloma; este espacio está conformado principalmente por mujeres de la zona. En las paredes blancas se visualizan carteleras con instructivos de cómo proceder en los espacios del taller, una de ellas contiene imágenes en blanco y negro con dibujos de decoración indígena. Al fondo se observa un gran horno eléctrico, donde las cerámicas elaboradas esperan en estanterías su turno para ingresar. La visita a este taller nos permitió dialogar con sus integrantes (mujeres de diferentes edades y trayectorias) y observar las materias primas, las cerámicas elaboradas en sus distintos niveles de confección, sus formas (utilitarias o no), colores y diseños empleados. También pudimos indagar sobre el interés de estas artesanas por conocer técnicas, procedimientos, formas y acabados prehispánicos. 
Por otro lado se entrevistaron a ceramistas de Valizas, Castillos, Santa Isabel de La Pedrera y La Paloma. Cada ceramista tiene su particularidad a la hora de elaborar su cerámica, su marca. Los talleres se encuentran dentro de las casas de los ceramistas o en el mismo predio; algunos grandes y amplios mientras otros son pequeños. Lo que tienen en común es la dedicación y el gusto por el trabajo con el barro. Las arcillas utilizadas en cada uno de los talleres varía, algunos emplean arcillas locales mientras otros compran la arcilla. Se desprende del diálogo con los interlocutores el conocimiento y la experimentación con las arcillas locales donde cada ceramista recorre el territorio en busca de arcillas de mejor calidad; estas fuentes de aprovisionamiento están en lugares cercanos ya identificados. Si bien algunas de las personas entrevistadas actualmente cocinan sus cerámicas en hornos a leña de elaboración propia, en su mayoría utilizan un horno eléctrico para la cocción de las piezas creadas. La elaboración es personal y está ligada tanto a los gustos del artesano como al lugar donde se colocan. Se observaron, por ejemplo, piezas tales como instrumentos musicales (ocarinas con forma de pájaros, udu), recipientes contenedores (platos, ollas, mates, vasijas, etc.), macetas, candelabros, figuras abstractas, antropomorfas, etcétera.

El diálogo con ceramistas arrojó para el equipo universitario datos sorprendentes sobre fuentes, técnicas, conocimiento del entorno y posibles sitios arqueológicos.

3) Prospecciones y caracterización de las gredas locales: la identificación y registro de fuentes potenciales de materias primas se vio orientada a partir de los contactos con artesanos locales.
Las prospecciones en varios casos fueron realizadas también en conjunto con los ceramistas. Tras la localización y registro (localización puntual con GPS) de las fuentes (Figura 2) fueron recolectados distintos tipos de arcilla. El proceso identificación de zonas de suelos arcillosos (afloramiento) tras la prospección, sigue con la comprobación manual y empírica sobre su plasticidad. ${ }^{9}$ Extraídas las muestras (dos de cada sitio), se rotularon e identificaron, tras lo cual se analizó la posible combinación natural con partículas calcáreas. Se secaron y molieron pequeñas porciones para luego hidratarlas al $100 \%$ de agua en envase de vidrio y así verificar el grado y porcentaje de decantación de partículas pesadas (principalmente arena) y el sobrenadado de partículas orgánicas.

Los materiales extraídos difícilmente se encuentran puros en la zona de Rocha; contienen arenilla de diverso tamaño, trozos de conchillas, pequeñas piedras, restos orgánicos como raíces y sales disueltas. El componente que más puede influir en el resultado final es la arena, aunque todas estas «impurezas" funcionan también como antiplásticos. Una vez obtenida la pasta, si es necesario se agregan los minerales que funcionarán como antiplásticos, pueden hallarse directamente en la naturaleza y pueden ser incorporados con distinto calibre de molienda, aportando así, características distintas. Las etapas siguientes, de modelado, son las que demuestran los diferentes grados de experiencia empírica en la alfarería tradicional y las que varían no solo como una característica propia en cada comunidad (aunque pueda haber intercambio cultural aquí y allá) sino que también están condicionadas por el material, por el destino final

9 Nos damos cuenta cuando una arcilla es trabajable y plástica mediante el amasado, la torsión, si responde como un material con memoria a la presión y manipulación. 
de la pieza a elaborar y por la forma de cocción.

Se elaboraron para cada muestra tablillas indicadoras de índice de contracción al secado y pequeños cuencos para comprobar si aparecían grietas en la etapa de secado al aire. Todas ellas fueron horneadas, aportando datos concretos sobre las características finales: color, resistencia práctica, permeabilidad, contracción total, posibilidad de observar el canto de trozos partidos, etcétera.

Esto permite obtener un mapa preliminar de las posibles fuentes locales de aprovisionamiento de arcillas para la confección cerámica y sus características principales. A futuro, tras los análisis químicos que se realizarán a las muestras, será posible la comparación más detallada de estas materias primas con las de las cerámicas arqueológicas.

4) Realización de talleres experimentales: se realizó un taller de cerámica experimental abierto a la comunidad, donde participaron estudiantes, ceramistas locales, niños/as, vecinos y vecinas del CURE sede Rocha y zonas aledañas, realizado en dos etapas, una de elaboración y la segunda de horneado (cocción).

La primera etapa estuvo vinculada a la introducción y elaboración de la cerámica a través de técnicas ancestrales (preparación de la arcilla, amasado, modelado por rodete, pastillado, etc.). Las arcillas para el taller fueron recolectadas en la localidad de Castillos a 57 km de la ciudad de Rocha en un lugar indicado por Ruiz Sena (conocido ceramista local) quien, además, nos acompañó durante la extracción de las muestras.

En esta instancia de trabajo se intercambió con las/los participantes sobre las características de las cerámicas arqueológicas del este del Uruguay (pastas, formas de cocción, formas, acabados, diseños, etc.) y sobre aspectos técnicos tales como la preparación de la masa, el empleo de diferentes antiplásticos presentes en la zona y las pruebas rápidas a la hora de elegir una arcilla adecuada de las que teníamos.

La experimentación se realizó en dos talleres paralelos, uno con adultos y otro con niños y niñas de entre cinco y diez años de edad.

Una segunda instancia, realizada veinte días más tarde, permitió que las piezas elaboradas perdieran la humedad necesaria para su cocción. Esta se realizó a cielo abierto, técnica inferida a través de los estudios arqueológicos de la cerámica indígena. Para ello, se preparó una estructura de madera con apoyo del ceramista argentino Tato Corte, que cuenta con una gran experiencia en cerámica indígena (véase, por ejemplo, Corte, 2017). Esta jornada tuvo distintas etapas, en primer lugar se construyó el pozo de quemado donde se preparó el fuego y las brasas a partir de leña y ramas finas con las que se mantenía el calor, luego sobre dicho pozo se instaló una estructura tipo parrilla, construida por los asistentes a partir de varas verdes, en donde se dispusieron las piezas para terminar su secado ya que es necesario que, antes de la quema, la arcilla pierda toda el agua de moldeo para poder acelerar la cocción minimizando el riesgo agrietamiento. Durante este proceso el fuego se mantiene incorporando leña y ramas finas para conservar el calor teniendo el cuidado de no generar llamas. Una vez que las piezas están secas, se retiran de la parrilla y se ponen directamente en las brasas y rescoldo para la finalización del proceso, el que se extendió por 6 horas aproximadamente (Figura 3).

Para finalizar la jornada, se reunieron los asistentes, ceramistas y el equipo de arqueología para realizar un intercambio 
acerca de la experiencia y establecer semejanzas entre los hallazgos surgidos a partir del taller y los fragmentos de cerámica indígena encontrada en sitios arqueológicos de Laguna de Rocha. El intercambio permitió también generar un análisis preliminar de las piezas creadas a partir de las materias primas locales.

\section{Reflexiones finales}

\section{y perspectivas de trabajo a futuro}

- l proyecto nos dejó diferentes reflexiones sobre la experiencia, en la cual participaron una multiplicidad de actores sociales de diferentes edades y profesiones. Consideramos que el proyecto aunque corto en el tiempo, fue muy enriquecedor para el equipo principalmente; así como la participación y entusiasmo por parte de los diferentes actores en cada instancia fue muy buena. El intercambio generado nos permitió conocer y experimentar con arcillas locales en diálogo con la población local, y comenzar el mapeamiento de las canteras locales.

La experimentación, la materialidad y la información aportada tanto por el equipo de arqueólogos/as como por los ceramistas, sumado al interés por conocer acerca del pasado indígena de la zona donde habitan hoy la mayor parte de los participantes, impulsó una sinergia en la interpretación de los materiales cerámicos y en la apropiación del conocimiento generado.

El camino recorrido nos permitió intercambiar y reflexionar en torno a la problemática abordada vislumbrando respuestas a algunas interrogantes planteadas. El trabajo interdisciplinario implicó un desafío por parte del equipo, donde las fronteras disciplinares muchas veces se vieron presentes. Esto se vio reflejado particularmente en el lenguaje utilizado por parte de cada integrante. Esto motivó instancias de intercambio a la interna para incorporar, acordar y repensar términos naturalizados.

El diálogo con la comunidad y su participación en las distintas etapas del

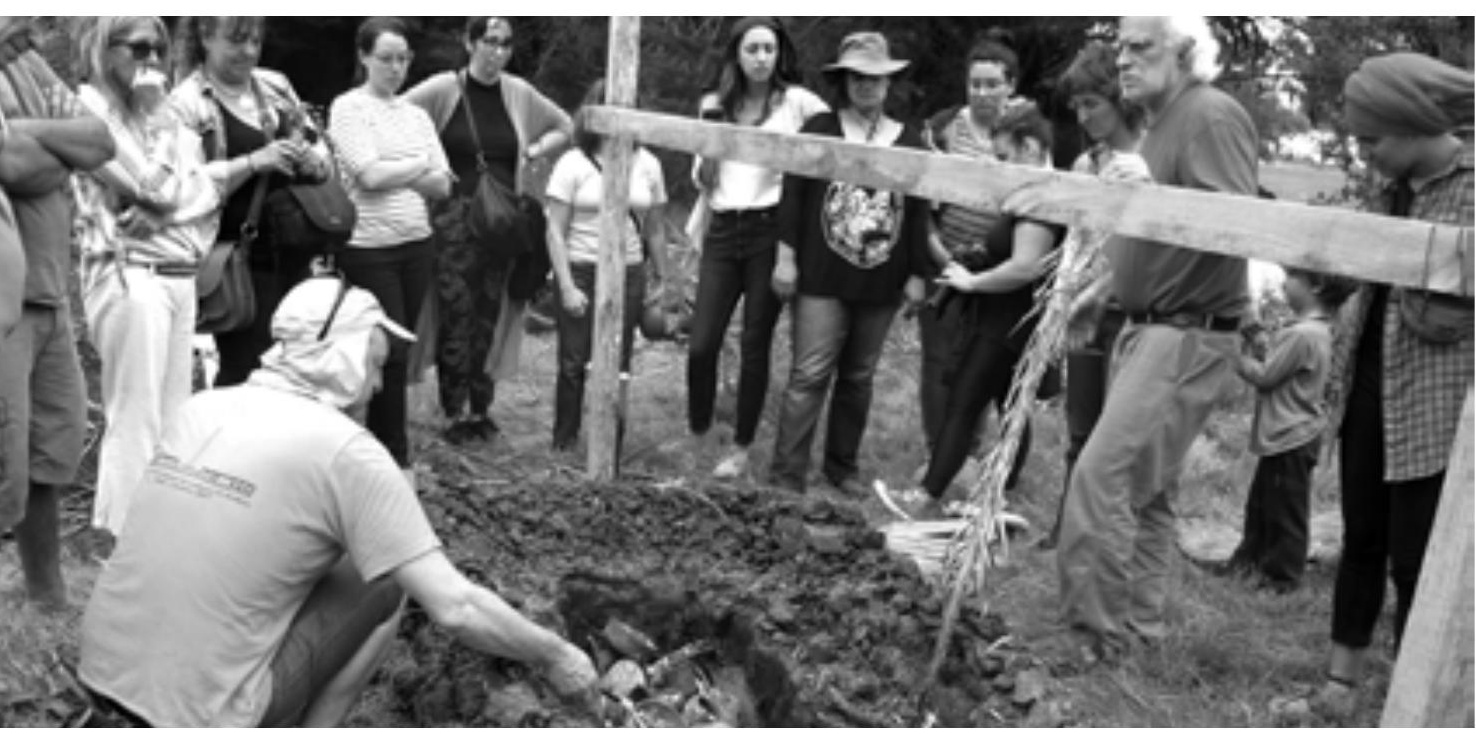


proyecto son de suma importancia. Más allá de las preguntas y los datos aportados por los actores sociales participantes en las instancias experimentales (fueron ámbitos de reflexión por ejemplo el calibre y cantidad de partículas antiplásticas, pequeños rasgos de decoración, características específicas de alcalinidad de las arcillas costeras rochenses, sus índices de contracción, tipo y temperaturas de cocción, etc.) el mayor logro del proyecto se habrá debido, tal vez, a que generó nuevas interrogantes y teorizaciones en estado germinal, tales como las horas del día más propicias para la cocción, el agregado o no de fundentes dentro de las pastas originarias, los análisis químicos de fragmentos salidos de la cocción actual para su comparativa con los fragmentos prospectados en antiguos sitios arqueológicos, los decorados a base de óxido de hierro prospectado o ungüentos rojizos, el uso o no del bruñido como impermeabilizante e indicador de temperatura, entre otros.

El proyecto fue un aporte más para el conocimiento sobre la tecnología cerámica prehispánica, así como una profundización del lenguaje plástico. Por otra parte, se trata de una indagación y reflexión colectiva sobre los sentidos cerámicos locales actuales y pasados. Los talleres también fueron parte de un registro audiovisual que a futuro se espera poder seguir trabajando para generar productos de divulgación y materiales didácticos para la enseñanza y la educación patrimonial. Esperamos también que a través de ellos se contribuya al desarrollo local con nuevos elementos para la socialización del conocimiento y productos para el turismo sostenible del área que recuperen los conocimientos prehispánicos y tradicionales, revalorizando los saberes locales y promoviendo la apropiación del pasado indígena de la zona.

\section{Agradecimientos}

$\triangle$ gradecemos desde ya a todos y todas las participantes del proyecto, esperando poder continuar las actividades conjuntas que recién comenzaron. Agradecemos a las autoridades del CURE por autorizar el desarrollo de los talleres en su sede de Rocha. Queremos agradecer muy especialmente a Tato Corte por todas sus enseñanzas y conocimientos compartidos.

\section{Bibliografía}

BlasCO, J. (2013). Elaboración de modelos digitales tridimensionales de materiales arqueológicos cerámicos. Un aporte a la discusión sobre funcionalidad. En: CABRERA, L. (Ed.). Anuario de Arqueología 2013 (pp. 149-182). Montevideo: Departamento de Arqueología, FHCE, Universidad de la República. Recuperado de <http://www.anuarioarqueologia. fhuce.edu.uy>.

BLASCO, J. (2014). Valoración de utilidad, percepción y apropiación social del Sistema de información Patrimonial del Uruguay (SIPAU) como herramienta de construcción gestión patrimonial. En: En_clave Inter. Montevideo: El, Universidad de la República.

BlAsCO, J. (2019). Abordaje arqueológico y patrimonial de artefactos de molienda de colecciones de Laguna de Rocha. Trabajo Monográfico Curso Taller II de Investigación en Arqueología. Montevideo: Departamento de Arqueología, FHCE, Universidad de la República [Inédito].

Blasco, J.; Lamas, G.; Gentile, B.; Villarmarzo, E. y GIANOTTI, C. (2014). Aprendiendo de nuestras prácticas. Sistematización del proyecto Cartografiando patrimonios. Cartografía social en Laguna de Rocha. En: BerRUtTI, L.; CABO, M. y DABEZIES, M. J. (Eds.). Apuntes para la acción III. Sistematización de experiencias de extensión universitaria. Montevideo: Extensión Libros, CSEAM, Universidad de la República.

CORTE, T. (2017). Aprendiendo Wizún. Experiencias y reconstrucción de la cerámica mapuche en Pampa y Patagonia. 
Bahía Blanca: Cuadernos de tapas durasBahía Blanca Che-Asociación Cultural de Defensa y Promoción de las Artes Regionales.

DiconCA, C. (2008). Arte y diseño para la resignificación de la prehistoria del Uruguay. Proyecto Tipolndígenas. Montevideo: CSIC, Universidad de la República.

FUTURO SUSTENTABLE S.A. (2011). Consultoría técnica para apoyar la elaboración del plan de manejo del Paisaje Protegido Laguna de Rocha Montevideo: Futuro Sustentable S.A.

GIANOTTI, C. y VILlarmarzo, E. (2011). Relevamiento arqueológico rápido, identificación de elementos culturales de conservación del Área Protegida Laguna de Rocha. Actividad 4, Tarea 4.5. Consultoría técnica para apoyar la elaboración del plan de manejo del Paisaje Protegido Laguna de Rocha. Montevideo: Futuro Sustentable S.A.

Gianotti, C.; Villarmarzo, E. y Blasco, J. (Eds.) (2015a). Una laguna Muchas Lagunas. El Paisaje Cultural Laguna de Rocha. Montevideo: Laboratorio de Arqueología del Paisaje y Patrimonio el Uruguay, FHCE, Universidad de la República.

Gianotti, C.; Villarmarzo, E.; PiazZA, N.; Lembo, V.; RodRíGUeZ-GALleGo, L. y NIN, M. (2015b). El Paisaje Cultural Laguna de Rocha como objeto focal de conservación: propuesta para su integración dentro del plan de manejo de un área protegida. En: MEDINA, M. (Coord.). Paisaje > patrimonio > proyecto territorial > desarrollo local (pp.12-31). Montevideo: Facultad de ArquitecturaCSIC, Universidad de la República.

Gianotti, C.; Villarmarzo, E.; Blasco, J.; Lamas, G.; GenTILE, B. y BICA, C. (2016). Paisaje y Patrimonio como espacios de construcción multivocal en el área protegida de Laguna de Rocha. En: GIANOTTI, C.; Barreiro, D. y VienNI, B. (Coords.). Patrimonio y multivocalidad. Teoría, práctica y experiencias en torno a la construcción conocimiento en patrimonio (pp. 191-212). Montevideo: CSIC, Universidad de la República.

INSTITUTO ESCUELA NACIONAL DE BELLAS ARTES (IENBA) (s/d). Una experiencia educacional 1960-1970. Montevideo: IENBA, Universidad de la República.
IENBA (2005). Proyecto Tecnologías multimedia para la investigación y difusión de conocimiento. Montevideo: IENBA, Universidad de la República.

lamas, G.; Blasco, J.; Bica, C.; Gentile, B. y GIANOTTI, C. (2013). La cartografía social como herramienta para la co-construcción del patrimonio cultural de Laguna de Rocha. En: Memorias del I Congreso de Extensión de la Asociación de Universidades Grupo Montevideo (AUGM)-Extenso 2013. Montevideo: Universidad de la República.

MAROZZI, Ó. y LAMAS, G. (2012). Catálogo de la colección arqueológica Enrique Zunini [Inédito]. Montevideo: Archivo del LAPPU, FHCE-CURE, Universidad de la República.

MINISTERIO DE VIVIENDA, ORDENAMIENTO TERRITORIAL Y MEDIO AMBIENTE (MVOTMA) e INTENDENCIA DEPARTAMENTAL DE ROCHA (IDR) (2016). Plan de manejo. Paisaje Protegido Laguna de Rocha. Rocha: MVOTMA.

VIENNI, B. y BLASCO, J. (2014). Museos y socialización del patrimonio arqueológico en Uruguay. Museología e Patrimônio. Revista Eletrônica do Programa de PósGraduação em Museologia e Patrimônio, 7 (2), 36-59. Recuperado de <http:// revistamuseologiaepatrimonio.mast. br/index.php/ppgpmus/issue/view/20/ showToc>.

VITANCURT, J. (2016). La gestión de Paisaje Protegido Laguna de Rocha como proceso participativo, de diálogo y construcción de confianzas. En: GIANOTTI, C.; BARReIRo, D. y VienNi, B. (Coords.). Patrimonio y multivocalidad. Teoría, práctica y experiencias en torno a la construcción conocimiento en patrimonio (pp. 147-159). Montevideo: CSIC, Universidad de la República.

VILLARMARZO, E. (2017). Las lagunas costeras y su rol en la ocupación de las tierras bajas: el caso de Laguna de Rocha. Cadernos do Lepaarq, 14 (28), 37-58.

Villarmarzo, E. (2018). Gestión integral del patrimonio arqueológico costero. Investigación y extensión en dos casos de estudio: Parque Nacional Cabo Polonio y Paisaje Protegido Laguna de Rocha. Tesis doctoral. Olavarría: Facultad de Ciencias Sociales, Universidad del Centro de la Prov. de Buenos Aires. 